\title{
Veel potentie voor zakelijke mediation
}

\section{Wat zijn de ervaringen van de afnemers van zakelijke mediation en welke ontwikkelingen in het vakgebied zien zij graag?}

\author{
Manon Schonewille \& Marc Simon Thomas
}

Eind 2018 verscheen het rapport 'ZAM/ACB Onderzoek naar kansen en belemmeringen voor zakelijke mediation'. ${ }^{1}$ Het doel van het onderzoek was om kennis en inzicht te verwerven in kansen en belemmeringen voor zakelijke mediation in Nederland. Om die reden is gekozen voor een onderzoek onder advocaten (in hun hoedanigheid van doorverwijzers naar mediation en adviseurs van bedrijven) en bedrijven (gebruikers van de diensten) die ervaring met zakelijke mediation hebben en ook onder rechters. Dit onderzoek geeft echter vooral de mening weer van ervaren gebruikers. De bevraagde rechters (in hun hoedanigheid van doorverwijzers) hadden ten dele ervaring met doorverwijzen naar mediation. ${ }^{2}$ Het onderzoek kan worden gezien als een vervolg op de Global Pound Conferences 2016-2017³ en het ACB-onderzoek uit 2004. ${ }^{4}$ Het ZAM/ACB-onderzoek gaat ech-

1 M. Simon Thomas, M. de Kort-de Wolde, E. Schutte \& M. Schonewille, ZAM/ACB Onderzoek naar kansen en belemmeringen voor zakelijke mediation, Utrecht: Montaigne Centrum voor Rechtsspraak en Rechtspleging 2018. Hierna: ZAM/ACB-onderzoek, te raadplegen op: www.uu. nl/nieuws/onderzoeksrapport-naar-zakelijke-mediation-in-nederland.

2 Er is gekozen voor een onderzoek onder diegenen die ervaring hebben met zakelijke mediation. Voor de advocaten en de bedrijven is deze aanpak onverkort doorgevoerd. Voor de rechterlijke macht hebben we op verzoek van de Raad voor de rechtspraak een uitzondering gemaakt door ook rechters zonder ervaring met doorverwijzing naar zakelijke mediation in het onderzoek te betrekken.

3 In 2014 bleek uit een onderzoek bij de deelnemers aan een pilot Global Pound Conference (GPC) in Londen, dat de behoeften van afnemers van mediationdiensten niet aansluiten bij de ideeën van de aanbieders. Er was verder onderzoek nodig om een antwoord te krijgen op de vragen: 'Wat willen zakelijke cliënten nu écht en wat betekent dat voor het aanbod van geschiloplossingsmechanismen in de toekomst?' Daarom is in 2016 en 2017 in 31 landen in totaal veertig keer een GPC gehouden. De congresdeelnemers kregen gestandaardiseerde multiplechoicevragen voorgelegd en aan de hand van antwoorden discussieerden ze met de panelleden. Nederland was op 1 juni 2017 aan de beurt (de Nederlandse resultaten zijn hier te vinden: www.imimediation.org/ research/gpc/series-data-and-reports/\#906-local-voting-results). Het voorlopige GPC Report van Herbert Smith Freehills (Global Pound Conference: Global Data Trends and Regional Differences) is in 2018 verschenen. Het definitieve rapport van de Global Pound Conference verschijnt naar verwachting in 2019 (www.globalpound.org/download/397/gpc-series-final-report/9775/gpc -series-global-data-trends-and-regional-differences.pdf) (laatst bezocht op 26 februari 2019).

4 M. Schonewille, Winst maken bij het oplossen van geschillen: conflictmanagement en mediation in Nederlandse ondernemingen, Den Haag: ACBMediation 2004. Hierna: ACB 2004, onder andere te raadplegen op: http://toolkitcompany.com/data/files/Resource\%20center/Research \%20and\%20surveys/marktonderzoek_rapport\%20ACB\%202004.pdf (laatst bezocht op 2 maart 2019). 
ter meer de diepte in en onderzoekt specifiek waaraan behoefte bestaat bij de afnemers, de bedrijven en advocaten, en waaraan juist niet. In dit artikel bespreken wij de belangrijkste onderzoeksbevindingen voor de drie doelgroepen, met een accent op hoe de afnemers van zakelijke mediation in Nederland denken over de potentie van mediation.

\section{Uitvoering van het onderzoek}

Het onderzoek is uitgevoerd door de vereniging Zakelijke Mediation (ZAM), de stichting ADR Centrum voor het Bedrijfsleven (ACB) in samenwerking met het Montaigne Centrum voor Rechtsstaat en Rechtspleging van de Universiteit Utrecht. De publicatie van het eindrapport is de schriftelijke vastlegging van een onderzoek naar zakelijke mediation dat in de zomer van 2018 is uitgevoerd onder advocaten, het bedrijfsleven en rechters. Het betreft een empirisch, kwalitatief onderzoek, waarbij gebruik is gemaakt van online vragenlijsten (enquêtes). De enquêtes bestonden uit drie vragenlijsten, voor elk van de drie doelgroepen een op maat gesneden versie, waarbij is gezorgd voor voldoende overlap tussen de drie verschillende enquêtes om zo een vergelijking tussen de drie doelgroepen mogelijk te maken.

\section{Opmerkelijke inzichten en de grote vraag die ook na dit onderzoek blijft; de mediationparadox}

Het merendeel van de bedrijven en advocaten is positief over hun ervaring met mediation, wat in scherp contrast staat met hun oordeel over de effectiviteit van een rechtsgang. Het gemiddelde rapportcijfer voor de mediator, de oplossing en het proces schommelt rond de 7,5 en in ruim driekwart van de zaken is het gelukt om (geheel of ten dele) een regeling te treffen. Bijna alle advocaten in dit onderzoek zien de toegevoegde waarde van een mediator, ook in gevallen waar het hen zelf niet gelukt is een regeling met de wederpartij te treffen.

De meeste bedrijven en ook hun advocaten zijn niet overtuigd van de effectiviteit van een juridische procedure. Gevraagd naar de meest effectieve vorm van geschiloplossing noemt slechts $2 \%$ van de bedrijven en $4 \%$ van de advocaten een rechtszaak. ${ }^{5}$ Ook rechters zijn er niet van overtuigd dat een rechtszaak partijen altijd verder helpt. Ongeveer $30 \%$ van de rechters geeft aan dat door een rechterlijke uitspraak het eigenlijke geschil tussen partijen wordt opgelost. Mediation, vooral ook in combinatie met een rechtsgang, wordt vaak genoemd als aantrekkelijke optie. Ten slotte 'bekend maakt bemind': veel gebruikers geven aan dat zij bereid zijn vaker mediation in te zetten nu ze eenmaal ervaring hiermee hebben. Doen deze resultaten dan ook vermoeden dat mediation een grote vlucht zal nemen en binnenkort de logische eerste stap zal zijn om een geschil op te lossen? De grote vraag die ook na dit onderzoek blijft, is waarom bedrijven in de praktijk toch nog zelden gebruikmaken van mediation, terwijl er wel veel rechtszaken en

5 Van de bevraagde advocaten en bedrijven noemt $4 \%$ arbitrage als het meest effectief. 
arbitrages tussen bedrijven plaatsvinden: de zogenoemde mediationparadox. Zelfs dit onderzoek, waarin advocaten en bedrijven mediation de hemel in prijzen, illustreert dat mediation in de praktijk van de zakelijke advocatuur een grote uitzondering is. De ondervraagde advocaten met meer dan tien jaar werkervaring waren gedurende hun loopbaan hoogstens bij vijf mediations betrokken. Dit biedt stof tot nadenken en voor verder onderzoek.

\section{Ook advocaten moeten zich bekwamen in mediation}

In de toekomst wordt kennis van mediation cruciaal voor elke advocaat. Meer dan $80 \%$ van de bedrijven verwacht van de eigen advocaat dat deze mediationvaardigheden heeft en dat deze altijd de mogelijkheid van mediation onderzoekt en met de cliënt bespreekt. Bedrijven lijken graag het heft in eigen hand te houden. Opmerkelijk is dat ondanks de duidelijke wens dat de advocaat een pro-mediationhouding heeft, een zakelijke cliënt zich niet geroepen voelt om vervolgens het advies van de advocaat om voor of tegen mediation te kiezen, te volgen.

De praktijk leert dat de snelheid van het proces en de kwaliteit van de gevonden oplossingen toeneemt indien beide advocaten beschikken over mediationervaring en een passende mindset. Zij vormen dan geen mogelijke belemmering voor het proces, maar geven hieraan juist een extra dimensie. ${ }^{6}$

\section{Perspectief van de gebruikers op de gewenste aanpak en achtergrond van de mediator}

Net als advocaten vinden bedrijven ervaring in het bedrijfsleven bij een mediator belangrijk. Daarnaast geven veel advocaten en bedrijven de voorkeur aan een mediator met voldoende juridische kennis en stellen zij het op prijs dat er tijdens een mediation ruimte is om de juridische aspecten aan de orde te stellen. Voorafgaand aan een mediation wil men eerst de juridische sterktes en zwaktes in kaart brengen.

Ook blijkt belangrijk dat een mediator is aangesloten bij een mediatorsverband zoals de Mediatorsfederatie Nederland (MfN), het International Mediation Institute (IMI), het ADR Register, of dat de mediator deel uitmaakt van een mediationkantoor of samenwerkingsverband van mediators. Een zakelijke uitstraling is nodig en evenzeer een bedrijfsmatige aanpak. Een positionering als gespecialiseerde, ervaren en beroepsmatig werkende mediator is een pre. Zowel advocaten als bedrijven zijn minder enthousiast over mediators die dit vak 'erbij doen' buiten een professionele setting.

6 Slechts $20 \%$ van de bedrijven in dit onderzoek is het niet eens met de stelling 'in mijn ervaring werkt aanwezigheid van advocaten vaak belemmerend: regelingen komen moeilijker tot stand'. Dit komt overeen met eerder onderzoek, bijvoorbeeld IMI, 'IMI International Corporate Users ADR Survey January-March 2013'. www.fd.unl.pt/docentes_docs/ma/MFG_MA_23457.pdf (2013; laatst bezocht op 14 oktober 2018). 
Een zakelijke mediator doet er goed aan open te staan voor specifieke wensen van betrokkenen in een individueel geval. Qua aanpak tonen bedrijven en advocaten zich een voorstander van een proactieve en 'sturende' mediator; een mediator die stevig de regie in handen neemt, bijvoorbeeld door het geven van een inschatting van de kansen en risico's, om zo partijen naar een regeling te sturen of door het aanbieden van een mediator proposal voor een mogelijke oplossing als er te weinig voortgang in de onderhandelingen zit. Bijna $50 \%$ van de bedrijven vindt zelfs een bindend advies door de mediator bespreekbaar als de mediation niet slaagt, ook als men een dergelijk arrangement niet vooraf contractueel is overeengekomen via een multi-step ADR-clausule. Daarnaast geven zakelijke gebruikers er de voorkeur aan om met een individueel intakegesprek te starten, maar van een mediator die uitsluitend op en neer pendelt, zijn meesten geen voorstander (bijna 80\%).

$\mathrm{Bij}$ al die zakelijkheid moeten mediators niet vergeten om ook te blijven reflecteren op de emoties, de interactie tussen partijen en de achterliggende problemen en belangen. Niet voor niets geven advocaten, bedrijven en rechters aan dat een van de allerbelangrijkste taken van de mediator is om het overleg tussen partijen in goede banen te leiden, zodat zij op een constructieve wijze met elkaar in gesprek blijven of komen. Ook het uit de weg ruimen van emotionele barrières die aan het treffen van een regeling in de weg staan, wordt als toegevoegde waarde van een mediator genoemd.

Bedrijven stellen hun behoefte aan een snelle oplossing voor een geschil waarin zij verwikkeld zijn voorop. Daarbij hebben ze een pragmatische insteek. Zij hechten minder belang aan het 'zuiver willen houden' van de taakopvatting, waar mediators nogal eens op gefocust zijn. Er is een probleem en dat moet zo snel mogelijk opgelost worden. Tegelijkertijd geeft ongeveer de helft van de bedrijven aan dat zij soms een zaak liever willen uitprocederen om vast te laten stellen dat zij het gelijk aan hun kant hebben.

Samenvattend: vanuit het perspectief van de gebruikers beschikt een zakelijk mediator over specifieke mediationvaardigheden en is hij of zij in staat om naargelang de vereisten van een zaak een breed scala aan faciliterende, sturende en evaluatieve interventies toe te passen, om op die manier het geschil zo snel mogelijk uit de wereld te helpen. Men verwacht een gespecialiseerde beroepsmediator die is aangesloten bij een professioneel verband of mediationkantoor. Daarnaast vindt men voldoende kennis van de zakelijke en juridische materie een pre.

\section{Wanneer adviseert een advocaat mediation en wat zijn de keuzemotieven voor bedrijven?}

Als we specifiek naar advocaten kijken, dan komt uit het onderzoek sterk naar voren dat snelheid als een groot pluspunt van mediation ten opzichte van een juridische procedure wordt beschouwd. Dit is voor advocaten de belangrijkste reden om voor mediation te kiezen, gevolgd door het behoud of verbetering van de relatie.

Mediation, zo geven advocaten aan, kan ook nuttig zijn wanneer geen sprake is van een duurzame relatie tussen partijen, of wanneer de zaak al sterk is geësca- 
leerd. De voordelen van snelheid en behoud of verbetering van de relatie worden ook als voordelen van zakelijke mediation in de literatuur genoemd. ${ }^{7}$ Volgens advocaten zijn de doorgaans lagere kosten voor hen niet de doorslaggevende reden om hun cliënten mediation te adviseren. Deze uitkomst wijkt af van wat hierover in de literatuur wordt gesteld. Bijvoorbeeld de gedachte dat een snellere oplossing via mediation zou kunnen leiden tot minder inkomsten voor de advocaat. Dergelijke persoonlijke financiële overwegingen worden in dit onderzoek met klem van de hand gewezen. In ouder onderzoek, bijvoorbeeld in het ACBonderzoek uit 2004, werd dit wel als een belangrijke belemmering gezien. In het ACB-onderzoek uit 2004 is echter indirect bevraagd op dit punt (hoort u wel eens dat dit bij collega's een rol kan spelen?). Bovendien schakelen de advocaten die meegedaan hebben aan het ZAM/ACB-onderzoek aantoonbaar mediators in. Dat voor hen eventuele effecten op hun portemonnee geen afweging zijn, sluit niet uit dat het voor collega's zonder mediationervaring mogelijk wel een rol speelt.

Opmerkelijk is dat voor bedrijven de veronderstelde doorgaans lagere kosten voor hen evenmin de doorslaggevende reden zijn om voor mediation te kiezen. Uit de enquête onder bedrijven komt duidelijk naar voren dat, net als bij advocaten het geval was, vooral snelheid als een groot pluspunt van mediation wordt beschouwd. Eveneens blijkt dat de verwachting dat mediation tot behoud of verbetering van de relatie kan leiden voor bedrijven belangrijk is.

Er zijn geen algemene redenen uit het onderzoek gekomen wanneer mediation volgens de gebruikers ongeschikt is. Bij advocaten worden weerstand bij de cliënt en het meer druk kunnen uitoefenen via een rechtsgang het meest genoemd.

\section{Het perspectief van de rechters}

De belangrijkste reden voor rechters om te verwijzen naar mediation, zo blijkt uit het ZAM/ACB-onderzoek, is het besef dat mediation kan leiden tot behoud of verbetering van de relatie tussen partijen. Wat ook een rol bij verwijzing speelt, is dat rechters onderkennen dat er in een conflict meestal meer factoren spelen dan strikt juridische. Als de antwoorden van de rechters worden vergeleken met die van de advocaten en bedrijven, dan valt een aantal zaken op. Een belangrijke reden voor rechters om niet naar mediation te verwijzen is de weerstand van een van de - partijen om mee te werken aan mediation. Dit staat enigszins haaks op de bevindingen uit de enquêtes onder advocaten en bedrijven. Daaruit komt juist naar voren dat advocaten meestal geen moeite hebben om de cliënt richting mediation te bewegen en dat bedrijven het ook niet als lastig ervaren om hun wederpartij over te halen tot mediation. Wellicht dat ook hier een rol speelt dat de zakelijke respondenten in dit onderzoek allemaal ervaring met mediation

7 Zie bijvoorbeeld: A. Brenninkmeijer, D. Bonenkamp, K. van Oyen \& H. Prein, Handboek Mediation, Den Haag: Sdu Uitgevers 2017, of: Is 'mediation' een alternatief voor rechtspraak bij het beslechten van conflicten?, in: M. Hertogh \& H. Weijers (red.), Recht van onderop. Antwoorden uit de rechtssociologie, Nijmegen: Ars Aequi Libri 2011, p. 225-251. M. Schonewille, Toolkit Mediation. Resultaat bereiken als mediator, manager, mediation advocate en onderhandelaar, Den Haag: Boom Juridische uitgevers 2018. 
hebben en dat het in hun specifieke casus geen rol heeft gespeeld. Daaruit kan niet worden geconcludeerd dat deze zaken geen rol spelen in geschillen waarbij het niet lukt om een mediation te initiëren.

Een meerderheid van de rechters, net als bij advocaten en bedrijven, vindt het wenselijk, dat wanneer sprake is van een mediationclausule eerst mediation wordt geprobeerd voordat de rechter wordt aangezocht.

Wat de wijze van uitvoering van de mediation betreft, zijn rechters, veel minder dan advocaten en bedrijven, voorstander van een mediator die zich tegenover partijen uitlaat over de kansen en risico's van een zaak. Als vervolgens de rechters mét verwijservaring vergeleken worden met rechters zónder die ervaring, valt op dat rechters met verwijservaring meer het nut inzien van zakelijke mediation dan rechters zonder. Rechters met verwijservaring onderschrijven de specifieke kwaliteiten van mediators meer dan rechters zonder en zij staan ook positiever tegenover de tijdsbesparing van mediation ten opzichte van een procedure. Dus, net als bij advocaten en bedrijven, blijkt ook bij rechters: bekend maakt bemind. Als men eenmaal ervaring heeft met mediation, is men vaker bereid dit middel in te zetten.

\section{Hybride modellen - de toekomst?}

Een van de deelvragen betrof de mogelijkheden van mediation in combinatie met andere vormen van geschiloplossing. Zoals hiervoor besproken, wordt dit door de gebruikers over het algemeen als positief gezien. Over de vraag welke combinatie het beste is, verschillen advocaten, bedrijven en rechters van mening. Zowel advocaten als bedrijven geven aan dat alleen rechtspraak of arbitrage voor hen niet de meest effectieve vorm van geschilbeslechting is, maar dat de voorkeur uitgaat naar mediation of mediation in combinatie met rechtspraak of arbitrage. Wanneer expliciet gevraagd wordt naar de combinatie mediation en arbitrage (Med-Arb), dan blijken zowel advocaten, bedrijven als rechters hier neutraal tegenover te staan. Mediation in combinatie met de mogelijkheid van bindend advies door 'dezelfde' mediator wordt door bedrijven positief beoordeeld. Advocaten en rechters zijn hier minder enthousiast over. Ten slotte, rechters zien de combinatie van mediation en rechtspraak als een mogelijkheid om de maatschappelijke effectiviteit van de rechtspraak te vergroten.

\section{Conclusies en aanbevelingen}

Het ZAM/ACB-onderzoek leert ons dat er behoefte is aan een andere manier van geschiloplossing dan de klassieke rechtsgang. Er is veel potentie voor zakelijke mediation als dit op een voor bedrijven en hun advocaten aantrekkelijke wijze wordt aangeboden. Dit onderzoek biedt daarvoor aanknopingspunten en zakelijke mediators doen er goed aan deze ter harte te nemen.

Desondanks geeft het inspelen op de behoeften van de markt geen garantie dat zakelijke mediation dan vanzelf een volwaardige en veelgebruikte wijze van geschiloplossing wordt. Ook uit dit onderzoek komt geen duidelijke reden naar 
voren waarom in vergelijking met het aantal zaken dat bij de rechter komt in slechts een klein deel van het aantal conflicten zakelijke mediation ingezet wordt. Terwijl er in vergelijking met arbitrage of een rechtszaak een veel grotere waardering voor deze wijze van conflictoplossing uitgesproken wordt. Voer voor psychologen? In ieder geval een interessant vraagstuk voor verder onderzoek. Mogelijk ligt een deel van de oplossing in combinaties van een rechtsgang met mediation. Onderzocht zou moeten worden hoe hieraan het beste invulling kan worden gegeven.

Wellicht is er een belangrijke rol weggelegd voor advocaten. Als zij mediationvaardigheden hebben en hun betrokkenheid gebruiken om door te vragen naar de echte - ook niet juridische - belangen van hun cliënt en de wederpartij en deze, al dan niet met behulp van een mediator, kunnen vertalen naar duurzame oplossingen, dan zijn we al een eind op weg.

Ten slotte vergt mediation het engagement om actief van de gebaande paden af te willen wijken. Gebeurt dat niet, dan leidt dat ertoe dat partijen automatisch een juridische procedure ingezogen worden. Daarom kan het zijn dat voor een daadwerkelijke doorbraak van mediation een nieuwe impuls nodig is, bijvoorbeeld wetgeving die ervoor zorgt dat partijen moeten motiveren waarom ze geen mediation willen. Kortom: zakelijke mediators, bedrijven, advocaten, rechters en de politiek zijn allemaal aan zet. 